\title{
Early Prenatal Diagnosis of Conjoined Twins: Case Series
}

\section{Orkun Cetin $^{1^{*}}$, Zehra Kurdoglu ${ }^{2}$, Numan Cim $^{1}$, Recep Yildizhan ${ }^{1}$, Guler Sahin ${ }^{1}$, Mertihan Kurdoglu ${ }^{3}$}

\begin{abstract}
Introduction: Conjoined twins are complicated and unusual form of monozygotic twins. We present early prenatal diagnosis of three cases of conjoined twins by 2-dimensional (2D) ultrasound between 9-10 weeks of gestation.

Case presentation: In the first case, we prenatally diagnosed parapagus dicephalus dibrachus dipus with 2- dimensional ultrasound at gestational age of 10 weeks 4 days. In the second case, we detected parapagus dicephalus at the 10 weeks 2 days gestation. In the third case, we diagnosed thoracopagus at the 9 weeks 6 days of gestation, using $2 \mathrm{D}$ ultrasound. After proper counselling, all of the patients opted early pregnancy termination due to the poor prognosis of conjoined twins.

Conclusion: Early prenatal detection of conjoined twinning is important for the gestational course. Conjoined twinning could be identified in early first trimester with cautious and comprehensive view by experienced sonographers. Early and accurate prenatal diagnosis of conjoined twinning allows preferable counselling of the parents and gives a chance for early termination of pregnancy. Keywords: Conjoined twins, Pregnancy, Prenatal diagnosis
\end{abstract}

\section{Introduction}

Conjoined twins are described by the conjoint trunk region as a result of defective monozygotic twinning (1). The prevalance ranges from 1 in 50000 to 1 in 100000 births in the world. Conjoined twins are incidental and very rarely, uncorrelated with heredity, maternal age and parity (2). Conjoined twins are cathegorized by the location of fusion and are always connected at identical anatomic points. Although different types can be encountered, the most frequently types are thoracopagus (20\%$40 \%)$, omphalopagus (18\%-33\%) and parapagus (28\%) (3). There is no suspicion that accurate and early diagnosis of fetal malformations will affect the management and perinatal outcomes. In this report, we aimed to present the early prenatal diagnosis of three cases of conjoined twins by 2-dimensional (2D) ultrasound between 9-10 weeks of gestation.

\section{Case 1}

A 33-year-old, gravida 4, para 3 pregnant woman was referred to our tertiary perinatal center at a gestational age of 10 weeks and 4 days with a presumptive diagnosis of conjoined twins. She had a family history of twins. There was no consanguineous history and complications in previous pregnancies. On detailed sonographic examination the twins shared a common heart, two heads, a common body and one umbilical cord. The poor perinatal outcome of conjoined twins was told to the parents. Early termi- nation of the pregnancy was offered. After committee report, pregnancy was terminated. Fetal autopsy confirmed the diagnosis of parapagus dicephalus dibrachus dipus (Figure 1A).

\section{Case 2}

A 22-year-old, gravida 2, para 1, pregnant woman referred to our tertiary perinatal center at a gestational age of 10 weeks and 2 days with inconclusive findings on ultrasound examination. Her medical history was unremarkable and there was no family history of twins. 2D transabdominal and transvaginal ultrasound view demonstrated only one gestational sac, placenta and umbilical cord. The embryo had 2 heads with separate necks, common heart and fused thoraces. The final prenatal diagnosis was parapagus dicephalus (Figure 1B). After proper counselling, the patient prefered the termination of pregnancy. Fetal autopsy confirmed the prenatal diagnosis of parapagus dicephalus.

\section{Case 3}

A 28-year-old, gravida 2, para 1, pregnant woman was referred to our tertiary perinatal center at a gestational age of 9 weeks and 6 days with presumptive diagnosis of conjoined twins. She had no relevant family and medical history. After detailed ultrasonographic examination, twins were joined at the thorax (thoracopagus). There was separate 2 heads, a common

heart and one umbilical cord (Figure 1C). In the view of 


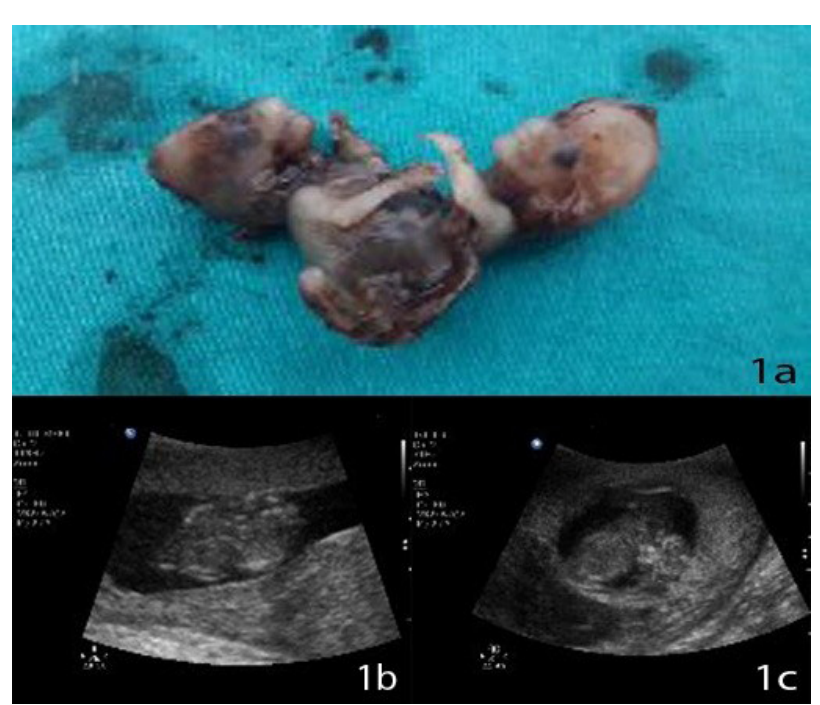

Figure 1. (A) Gross specimen of aborted parapagus dicephalus dibrachus dipus, 10 weeks and 4 days gestation (Case 1). (B) Transverse section of parapagus with 2D ultrasound, 10 weeks and 2 days gestation (Case 2). (C) A wide fetal pole with bifid view in thoracopagus with 2D ultrasound, 9 weeks and 6 days gestation (Case 3).

the poor fetal prognosis, the family opted to terminate the pregnancy.

\section{Discussion}

Conjoined twinning is the result of deficient cleavage of a unique blastocyst at 12-13 days after conception (4). This condition occurs in about $1 \%$ of monozygotic twins. Furthermore, they are the most curious condition for monozygotic twinning (5).

The first conjoined twin case was declared at late 1970s with many case reports in recent years. Chorionicity definition is the critical step for transabdominal or transvaginal view after scanning of separated gestational sacs. In our case series, we identified the fetal pathologies transabdominally. Sonographic features described for conjoined twins are without dividing membrane, adherent body regions and inseparable trunks or heads without transpositions of fetal movements (6).

Conjoined twins are now detected in the first trimester of gestation with the increasing use of ultrasound. Cardiac defects, congenital diaphragmatic hernia, neural tube defect, cystic hygroma, renal dysplasia, clubfoot and intestinal atresia are often viewed in conjoined twins (7). Early prenatal diagnostic findings of conjoined twins are double view of fetal pole, more than three vessels in the umbilical cord, persistence of 2 heads at the same plane of the fetal body view and no movements of the fetuses with each other (8). Sonographers could suspect the diagnosis of conjoined twinning at 7 weeks of gestation. The main differential diagnosis of conjoined twins in the first trimester is monochorionic monoamniotic twins. The prenatal detection is not simple in early first trimester all the time; normal monoamniotic fetuses could mimick conjoined twins in prior reports $(9,10)$. The index of doubt should appear by single yolk sac in a twin pregnancy or without a dividing amniotic membrane on ultrasound scanning. At eighth gestational week, there is an accelarating improvement in fetal movements and this condition enables sonographers to differentiate conjoined and nonconjoined monoamniotic twins (11). As in our cases, we made the correct diagnosis of conjoined twins between 9th and 10th weeks of gestation according to these sonographic markers.

First trimester transabdominal-transvaginal ultrasonography in combination with color Doppler and 3-dimensional (3D) ultrasound are important advances that allow for early prenatal diagnosis of conjoined twins (12). The earliest prenatally diagnosed conjoined twin case was 7 weeks and 6 days gestation in the medical literature reviewed in PubMed (13). In the presence of maternal obesity, oligohydroamnios and limited sonographic ability to differ soft tissues from each other, magnetic resonance imaging (MRI) provides an excellent and accurate alternative procedure. In our case series, we performed transvaginal-transabdominal 2D ultrasound and color Doppler imaging to diagnose conjoined twins.

There is no doubt that the perinatal prognosis is generally very poor among conjoined twins and associated with high perinatal mortality. Parents request detailed counselling about management alternatives such as continuation of pregnancy and planned neonatal surgery, pregnancy termination, multifetal pregnancy reduction or selective fetoside in cases of high-order multifetal pregnancies with a component of conjoined fetuses (14).

In our opinion, experienced sonographers could identify conjoined twinning in early first trimester with cautious and comprehensive view. The early prenatal detection of conjoined twinning is critical for the course of gestation. Thereby, obstetricians may give a better consultation to the parents in early gestational weeks and offer a chance for immediate termination of pregnancy.

\section{Ethical issues}

Written informed consent was obtained from the parents for publication of this case series and accompanying images.

\section{Financial Support}

The authors declared that this study has received no financial support.

\section{Conflict of interests}

The authors declared that there is no conflict of interests regarding the publication of this article.

\section{Acknowledgments}

We would like to thank all obstetricians in our clinic who helped us in this case series.

\section{References}

1. Martínez-Frías ML, Bermejo E, Mendioroz J, et al. Epidemiological and clinical analysis of a consecutive series of conjoined twins in Spain. J 
Pediatr Surg 2009;44(4):811-820. doi:10.1016/j. jpedsurg.2008.07.002.

2. Conjoined twins-an epidemiological study based on 312 cases. The International Clearinghouse for Birth Defects Monitoring Systems. Acta Genet Med Gemellol (Roma). 1991;40(3-4):325-335. doi: 10.1002/1096-8628(20000717).

3. Winkler N, Kennedy A, Byrne J, Woodward P. The imaging spectrum of conjoined twins. Ultrasound Q. 2008;24(4):249-255. doi:10.1097/ RUQ.0b013e31818c8858.

4. Machin GA, Keith LG, Bamforth F, eds. An atlas of multiple pregnancy: Biology and pathology. New York: Parthenon Publishing Group; 1999:13-24.

5. Opitz JM. Blastogenesis and the "primary field" in human development. Birth Defects Orig Artic Ser. 1993;29(1):3-37.

6. Tongsong T, Chanprapaph P, Pongsatha S. First trimester diagnosis of conjoined twins: a report of three cases. Ultrasound Obstet Gynecol. 1999;14(6):434437. doi:10.1046/j.1469-0705.1999.14060434.x.

7. Chen CP. Thoraco-omphalopagus conjoined twins associated with omphalocele and an umblical cord cyst. Taiwan J Obstet Gynecol. 2007;46(2):183-184. doi:10.1016/S1028-4559(07)60017-5.

8. Sharma UK, Dangol A, Chawla CD, Shrestha D.
Antenataldetection of conjoined twins. J Nepal Med Assoc. 2007;46(167):133-135.

9. Usta IM, AwwadJT. A false positive diagnosis of conjoined twins in a triplet pregnancy: pitfalls of first trimester ultrasonographic prenatal diagnosis. Prenat Diagn 2000;20(2):169-170.

10. Weiss JL, Devine PC. False positive diagnosis of conjoined twins in the first trimester. Ultrasound Obstet Gynecol. 2002;20(5):516-521. doi: 10.1046/j.1469-0705.2002.00849_1.x

11. Hill LM. The sonographic detection of early firsttrimester conjoined twins. Prenat Diagn 1997;17(10): 961-3.

12. Bonilla-Musoles F, Raga F, Bonilla F Jr, Blanes J, Osborne NG. Early diagnosis of conjoined twins using two-dimensional color Doppler and three-dimensional ultrasound. J Natl Med Assoc. 1998;90(9):552-556.

13. Taner MZ, Kurdoglu M, Taskiran C, Kurdoglu Z, Himmetoglu O, Balci S. Early prenatal diagnosis of conjoined twins at 7 weeks and 6 days' gestation with two-dimensional Doppler ultrasound: a case report. Cases J. 2009;2:8330. doi:10.4076/1757-1626-2-8330.

14. Pajkrt E, Jauniaux E. First-trimester diagnosis of conjoined twins. Prenat Diagn. 2005;25(9):820-826. doi: 10.1002/pd.1267.

Copyright (C) 2015 The Author(s); This is an open-access article distributed under the terms of the Creative Commons Attribution License (http://creativecommons.org/licenses/by/4.0), which permits unrestricted use, distribution, and reproduction in any medium, provided the original work is properly cited. 